Article

\title{
Preparation and Characterization of Multi-doped Porous Car- bon Nanofibers from Carbonization in Different Atmospheres and Their Oxygen Electrocatalytic Properties Research
}

\author{
Tao Wang 1, Oluwafunmilola Ola ${ }^{3}$, Qijian Niu 1,*, Yuhao Lu ${ }^{1}$, Malcom Frimpong Dapaah ${ }^{4}$, Liang Cheng ${ }^{4}$, Nan- \\ nan Wang ${ }^{2}$ and Yanqiu $\mathrm{Zhu}^{2, *}$
}

1 Key Laboratory of Modern Agriculture Equipment and Technology, School of Agricultural Engineering, Jiangsu University, Zhenjiang, Jiangsu, 212013, China; wangt073@163.com (T.W.); niuqijian@ujs.edu.cn (Q.J.N.); luyuhao1999@163.com (Y.H.L.)

2 Guangxi institute for Fullerene Technology, Key Laboratory of New Processing Technology for Nonferrous Metals and Materials, School of Resources Environment and Materials, University of Guangxi, Nanning, Guangxi, 530000, China; wangnannan@gxu.edu.cn (N.N.W.); y.zhu@gxu.edu.cn (Y.Q.Z.)

3 Advanced materials research group, University of Nottingham, Nottingham, NG7 2RD; Oluwafunmilola.ola1@nottingham.ac.uk (O.O.)

4 Institute of Environmental Health and Ecological Security, School of the Environment and Safety Engineering, Jiangsu University, Zhenjiang, 212013, China; 5103200301@stmail.ujs.edu.cn (M.F.D.); Clcheng@ujs.edu.cn (L.C.)

* Correspondence: niuqijian@ujs.edu.cn (Q.J.N.); y.zhu@gxu.edu.cn (Y.Q.Z.)

\begin{abstract}
Recently, electrocatalysts for oxygen reduction reactions (ORRs) as well as oxygen evolution reactions (OERs) hinged on electrospun nanofiber composites have attracted wide research attention. Transition metal elements and heteroatomic doping are important methods used to enhance their catalytic performances. Lately, the construction of electrocatalysts based on metal-organic framework (MOF) electrospun nanofibers has become a research hotspot. In this work, bimetallic $\mathrm{Ni}_{x} \mathrm{Co}_{y}$-ZIF nanocrystals were synthesized in an aqueous solution, followed by $\mathrm{Nix}_{\mathrm{x}} \mathrm{Co}_{\mathrm{y}} \mathrm{ZIF} / \mathrm{PAN}$ electrospun nanofiber precursors, which were prepared by a simple electrospinning method. Bimetal (Ni-Co) porous carbon nanofiber catalysts doped with nitrogen, oxygen, and sulfur elements were obtained at high-temperature carbonization treatment in different atmospheres (Ar, Air, and $\mathrm{H}_{2} \mathrm{~S}$ ), respectively. The morphological properties, structures, and composition were characterized by SEM, TEM, SAED, XRD, and XPS. Also, the specific surface area of materials and their pore size distribution was characterized by BET. Linear sweep voltammetry curves investigated catalyst performances towards oxygen reduction and evolution reactions. Importantly, Ni1 Co2-ZIFs/PAN-Ar yielded the best ORR activity, whereas Ni1 Co1-ZIFs/PAN-Air exhibited the best OER performance. This work provides significant guidance for the preparation and characterization of multi-doped porous carbon nanofibers carbonized in different atmospheres.
\end{abstract}

Keywords: electrospinning; porous carbon nanofibers; oxygen reduction reaction; oxygen evolution reaction

\section{Introduction}

Water splitting, metal-air batteries, and fuel cells are notable renewable energy technologies that rely heavily on oxygen reduction reactions (ORRs) and oxygen evolution reactions (OERs). Nonetheless, the slow kinetics of oxygen evolution and reduction reaction impedes their energy conversion efficiency [1]. Therefore, developing various oxygen reduction together with oxygen evolution catalysts is very important to improve their efficiencies. At present, $\mathrm{Pt} / \mathrm{C}$ and $\mathrm{RuO}_{2} / \mathrm{IrO}_{2}$ are the main commercial catalysts serving as 
ORR and OER catalysts [2,3]. However, they are both precious metal catalysts with a high price, low resource reserves, and low stability. In recent years, researchers have developed a variety of novel catalysts, mainly to reduce the use of precious metals to build non-precious metal catalysts. Among them, transition metal-carbon matrix composite catalysts have been widely studied. Many carbon-based materials (carbon nanoparticles [4], biochar [5], graphene [6], carbon nanotubes [7], carbon nanofiber [8], etc.) have become an important carrier for the construction of oxygen electrocatalysts because of their wide sources, cheap and easy to obtain, good electrical conductivity and diverse structures [9]. Transition metal (Fe, Co, Ni, Cu, Zn, etc.) or heteroatomic (N, P, S, O, etc.) doping is a common approach for preparing these catalysts [10,11]. Moreover, the performance and functionalization of the catalysts were improved through single doping to multiple doping. And even conversion between different forms of compounds from simple compounds to oxides [12], hydroxides [13], carbides [14], sulfides [15], phosphide [16], and their hybrids. They have achieved good catalytic performances.

Recently, the construction of oxygen electrocatalysts based on electrospun nanofibers has attracted much attention[17]. Electrospinning is a novel technology for preparing onedimensional nanofibers. Electrospun nanofibers have been commonly utilized in many domains due to their merits, such as high void fraction, large specific surface area, large aspect ratio, and small diameter[18]. Many electrospun nanofiber catalysts with different properties were prepared by transition metal and heteroatomic doping. The commonly used methods include direct pyrolysis of inorganic salts in electrospun nanofibers and insitu surface growth of electrospun nanofibers. However, these methods tend to cause agglomeration of doped nanoparticles, or the preparation steps are relatively complicated. Metal-organic frameworks (MOFs) are crystalline materials fabricated by merging metal ions and organic ligands through coordination bonds. A variety of high-performance oxygen electrocatalysts were prepared by changing the composition and carbonization conditions of MOF materials [19].

Further combination with electrospun nanofibers is beneficial for highly distributed active sites and porous carbon nanofiber catalysts preparation. The OER and ORR properties of bimetallic MOF electrospun structures show good dual-function performance [20]. However, carbonization of the same precursor in different atmospheres and conversion of different phases have not been reported. It is paramount to study the structure, composition, and properties of catalytic materials under different carbonization atmospheres for high-performance catalyst development.

Herein, firstly the bimetallic $\mathrm{Nix}_{x} \mathrm{Co}_{y}$-ZIFs nanocrystal materials were synthesized in aqueous solution; and then $\mathrm{Nix}_{x} \mathrm{CO}_{y}$-ZIFs/PAN nanofiber precursors were prepared by simple electrospinning method; at last, the multi-doped porous carbon nanofiber catalysts for OER and ORR were obtained by carbonization in different atmospheres (Ar, Air, and $\mathrm{H}_{2} \mathrm{~S}$ ). The morphologies, structures, crystal compositions, and elemental compositions of the precursors and derived catalysts after carbonization were characterized. Finally, the OER and ORR catalytic effects of various samples under different conditions were investigated.

\section{Experimental section}

\subsection{Materials}

Ethanol $(\geq 99.7 \%)$, N,N-dimethylformamide (DMF, $\geq 99.5 \%), \mathrm{Co}\left(\mathrm{NO}_{3}\right)_{2} \cdot 6 \mathrm{H}_{2} \mathrm{O}(99 \%)$, potassium hydroxide $(\mathrm{KOH}, 98 \%), \mathrm{Ni}\left(\mathrm{NO}_{3}\right)_{2} \cdot 6 \mathrm{H}_{2} \mathrm{O}(98 \%)$, polyacrylonitrile (PAN, molecular weight of $\left.150 \mathrm{Kg} \cdot \mathrm{mol}^{-1}\right)$, and 2-methylimidazole $\left(\mathrm{C}_{4} \mathrm{H}_{6} \mathrm{~N}_{2}\right.$, MIM) were obtained from Aladdin Biochemical Technology Co., Ltd (Shanghai, China). DuPont Co. supplied the Nafion solution $(5 \mathrm{wt} \%)$. The purchased chemicals were utilized as received without additional purification unless specified in this work.

\subsection{Preparation of Bimetal Nix $\mathrm{Co}_{y}$-ZIFs Nanocrystals}

$\mathrm{Ni}_{\mathrm{x}} \mathrm{Coy}_{\mathrm{y}} \mathrm{ZIF}$ nanocrystals were prepared with various molar ratios $(1,2$, and $4 \mathrm{mmol})$ of $\mathrm{Ni}\left(\mathrm{NO}_{3}\right)_{2} \cdot 6 \mathrm{H}_{2} \mathrm{O}$ added to 2-methylimidazole $(300 \mathrm{mmol})$ and $\mathrm{Co}\left(\mathrm{NO}_{3}\right)_{2} \cdot 6 \mathrm{H}_{2} \mathrm{O}(4 \mathrm{mmol})$. 
These precursors were then mixed in distilled water $(100 \mathrm{~mL})$ before continuous stirring at room temperature (RT) for $24 \mathrm{~h}$ [21]. This was accompanied by 10 min centrifugation and rinsing thrice with deionized (DI) water. Nix Coy-ZIF powders were obtained, with $\mathrm{x}$ and y representing $\mathrm{n}(\mathrm{Ni}) / \mathrm{n}(\mathrm{Co})$ molar ratio.

\subsection{Preparation of Bimetal NixCoy-ZIFs/PAN nanofibers}

$1.0 \mathrm{~g}$ of as-prepared $\mathrm{Ni}_{\mathrm{x}} \mathrm{Co}_{\mathrm{y}}$-ZIF nanoparticles, $0.5 \mathrm{~g}$ of PAN polymer, and $4.5 \mathrm{~g}$ of DMF solvent were mixed to prepare the electrospinning solution after stirring for several hours. The obtained mixture was transferred to a plastic syringe $(5.0 \mathrm{~mL})$ with a single nozzle (stainless steel) of $0.6 \mathrm{~mm}$ diameter. For the typical electrospinning procedure, the applied high voltage with set interval between the collector (aluminum foil) and tip were $20 \mathrm{kV}$ and $15 \mathrm{~cm}$, respectively. Also, the syringe injection speed was $0.6 \mathrm{~mL} . \mathrm{h}^{-1}$. After electrospinning, nanofibers from the aluminum foil were placed in a vacuum oven set to 80 ${ }^{\circ} \mathrm{C}$ overnight for residual solvent removal [22].

\subsection{Preparation of multi-doped porous carbon nanofibers}

The dried Nix $\mathrm{CO}_{\mathrm{y}}$-ZIFs/PAN nanofibers were heated in different atmospheres in a tube furnace. Three main cases were considered; (i) in Ar atmosphere: the $\mathrm{Ni}_{x} \mathrm{Coy}^{-}$ $\mathrm{ZIF} / \mathrm{PAN}$ precursor was heated at $800{ }^{\circ} \mathrm{C}$ for $2 \mathrm{~h}$ with $5{ }^{\circ} \mathrm{C} \cdot \mathrm{min}^{-1}$ heating rate, before cooling to room temperature; (ii) in Air atmosphere: after a carbonization process consistent with Ar atmosphere, the oxidation process was completed by heating for $2 \mathrm{~h}$ at $300{ }^{\circ} \mathrm{C}$ in an Air atmosphere with $5{ }^{\circ} \mathrm{C} \cdot \mathrm{min}^{-1}$ heating rate; (iii) in $\mathrm{H}_{2} \mathrm{~S}$ atmosphere: during a carbonization process consistent with Ar atmosphere, the sulfurization process was initiated when the temperature rose to $800{ }^{\circ} \mathrm{C}$, and $\mathrm{H}_{2} \mathrm{~S}$ gas was supplied at this temperature for $2 \mathrm{~h}$ continuously.

2.5. Material characterization

The morphological features of the synthesized catalysts were characterized by SEM (JSM-6701F, $5 \mathrm{kV}$ operating condition) and TEM (Tecnai G2 20 S-T win, $200 \mathrm{kV}$ operating condition). The crystal structure was characterized by an XRD pattern with $\mathrm{Cu} \mathrm{K} \alpha$ radiation (Bruker D8 Advance, $40 \mathrm{kV}$ operating condition). Elemental composition and doping state were characterized by XPS spectra on an ESCLAB 250 spectrometer. Pore size distribution and corresponding BET surface area were characterized using an Autosorb-iQ (Quantachrome) gas sorptometer by the standard volumetric procedure [23].

\subsection{Electrochemical measurements}

For electrochemical performance measurements in the prepared samples, all were done in a conventional three-electrode system, in which a Pt wire, an $\mathrm{Ag} / \mathrm{AgCl}$ electrode (3.0 $\mathrm{M} \mathrm{KCl}$ solution), and a GCE (glassy carbon electrode, $\mathrm{d}=4.0 \mathrm{~mm}$ ) functioned as the counter electrode, reference electrode, and the working electrode, respectively. On catalyst ink synthesis, the catalyst $(5.0 \mathrm{mg})$ was distributed in a water/ethanol $(\mathrm{v} / \mathrm{v}=4: 1)$ solution $(1.0 \mathrm{~mL})$ with added Nafion solution $(5.0 \mathrm{wt} \%, 5.0 \mathrm{uL})$ using ultrasonication for $0.5 \mathrm{~h}$. Afterward, catalyst ink $(5.0 \mu \mathrm{L})$ was spread onto the working electrode surface for further electrochemical measurements. The catalytic activities of OER and ORR were characterized by linear sweep voltammetry (LSV) curves set at $10 \mathrm{mV} . \mathrm{s}^{-1} \mathrm{scan}$ rates [24].

\section{Results and discussions}



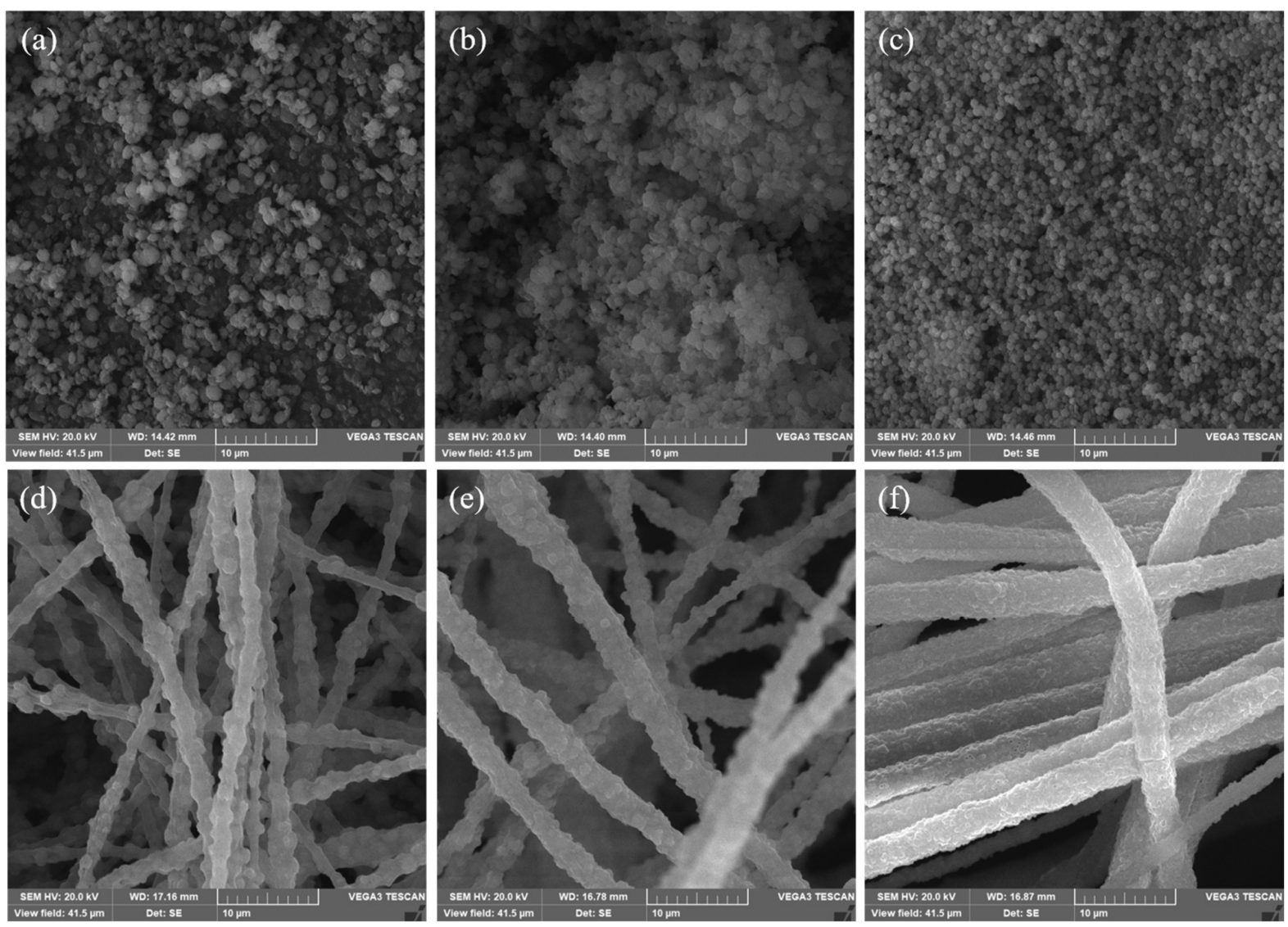

Figure 1. The SEM images of the prepared $\mathrm{Ni}_{x} \mathrm{CO}_{y}-\mathrm{ZIFs}$ crystals and $\mathrm{Ni}_{x} \mathrm{Co}_{y}-\mathrm{ZIFs} / \mathrm{PAN}$ nanofibers: (a) Ni1Co1-ZIFs; (b) Ni1Co2-ZIFs; (c) Ni1o-ZIFs; (d) Ni1Co1-ZIFs /PAN; (e) $\mathrm{Ni}_{1} \mathrm{Co}_{2}-\mathrm{ZIFs} / \mathrm{PAN}$; (f) Ni1으-ZIFs/PAN nanofibers.

The micro-morphologies of synthesized bimetallic $\mathrm{Nix}_{\mathrm{C}} \mathrm{Co}-\mathrm{ZIFs}$ and the $\mathrm{Ni}_{x} \mathrm{Co}_{y}-$ ZIFs/PAN nanofiber precursors were characterized by SEM images, as depicted in Figure 1. From Figure 1a-c, the bimetallic $\mathrm{Nix}_{x} \mathrm{Co}_{y}$-ZIFs appeared in the form of nanoparticles. With the increase of Co ratio, the morphology of nanoparticles became smaller as the diameter gradually decreased from Figure $1 \mathrm{a}$ to $1 \mathrm{c}$. As shown in Figure 1d-f, the $\mathrm{Nix}_{x} \mathrm{Coy}_{\mathrm{y}}$ ZIFs/PAN nanofibers had one-dimensional structures, with NixCoy-ZIF convex-like crystals coating its surface. In Figure 1f, the diameter of Ni1 $\mathrm{Co}_{4}-\mathrm{ZIF}$ /PAN nanofibers was more uniform due to the small diameter of the coated $\mathrm{Ni}_{1} \mathrm{Co}_{4}$-ZIFs particles. 


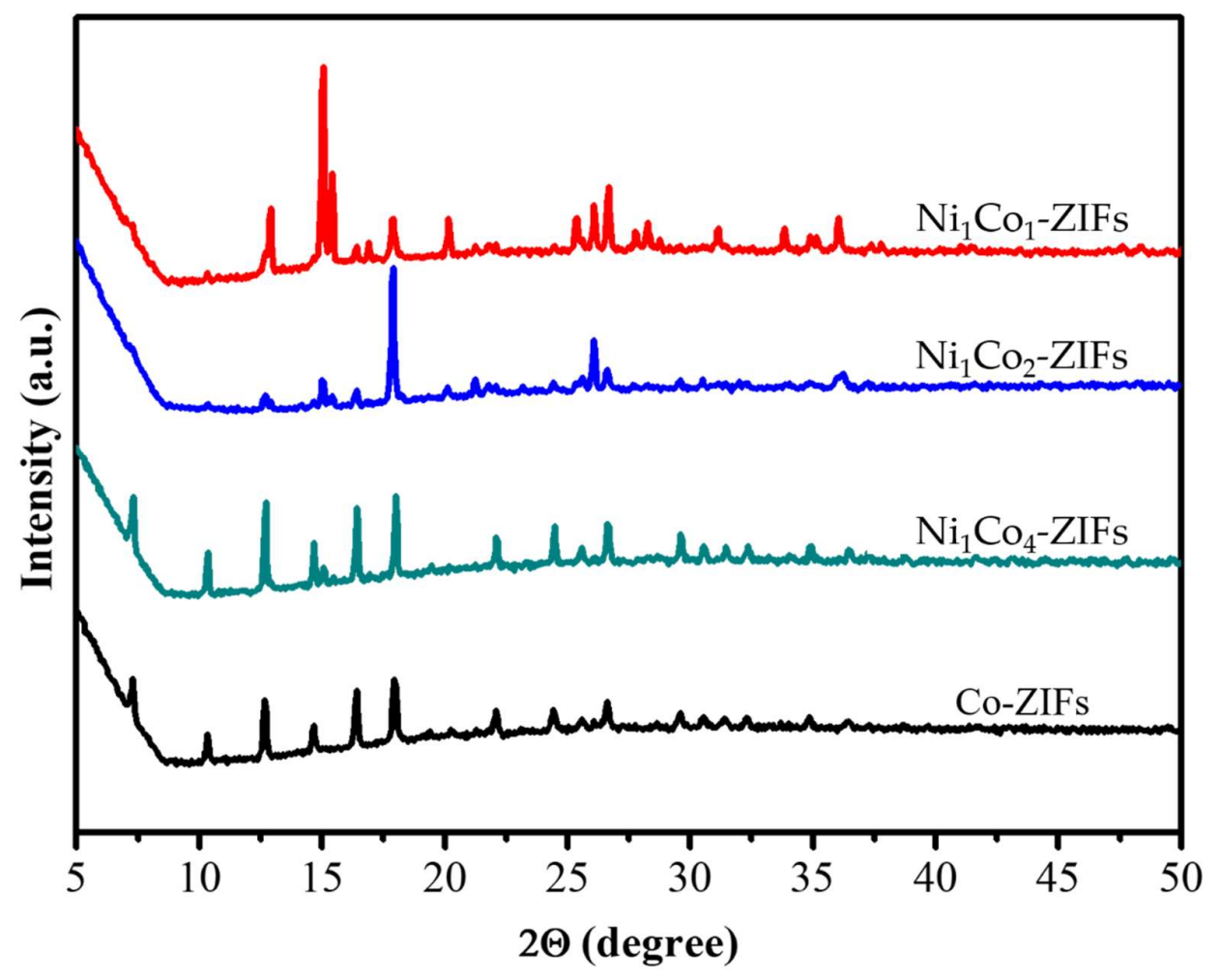

Figure 2. The XRD patterns of different $\mathrm{Nix}_{x} \mathrm{Co}_{y}$-ZIFs crystals: $\mathrm{Ni}_{1} \mathrm{Co}_{1}-\mathrm{ZIFs}$; $\mathrm{Ni}_{1} \mathrm{Co}_{2}-\mathrm{ZIFs}$; $\mathrm{Ni}_{1} \mathrm{Co}_{4}$-ZIFs, and Co-ZIFs.

The crystal structure of the synthesized bimetallic $\mathrm{Ni}_{x} \mathrm{CO}_{y}$-ZIF nanoparticles was characterized by XRD patterns illustrated in Figure 2. With the increase of Ni content, the crystal structure gradually disappeared. However, the crystal structure of $\mathrm{Ni}_{1} \mathrm{Co}_{4}-\mathrm{ZIF}$ was the same as the Co-ZIF. This was in consent with already reported works [21].
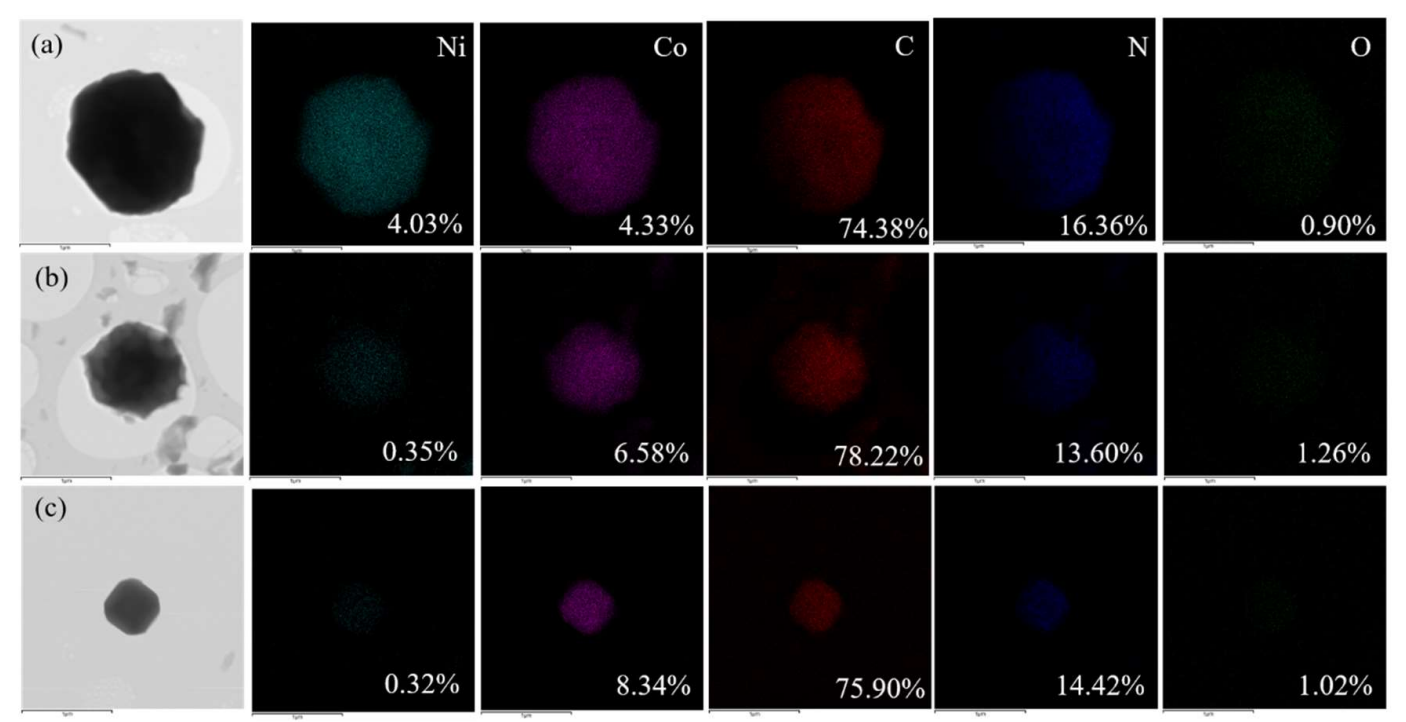

Figure 3. The TEM images and different elemental mappings of $\mathrm{Nix}_{x} \mathrm{CO}_{y}-\mathrm{ZIF}$ crystals: (a) $\mathrm{Ni}_{1} \mathrm{Co} 1-\mathrm{ZIFs}$; (b) Ni11 $\mathrm{Co}_{2}-\mathrm{ZIFs}$; (c) Ni1 $\mathrm{No}_{4}$-ZIFs. 
The content and distribution of various elements in the synthesized bimetallic $\mathrm{Ni}_{\mathrm{x}} \mathrm{CO}_{\mathrm{y}}$-ZIF nanoparticles were studied by TEM elemental mappings in Figure 3. The contents of $\mathrm{C}, \mathrm{N}$, and $\mathrm{O}$ elements in bimetallic Nix $\mathrm{Coy}_{\mathrm{y}}$ ZIF crystals had no significant difference. However, the proportion of $\mathrm{Ni}$ and $\mathrm{Co}$ was quite different. In Ni1Co1-ZIF crystals, the Ni:Co ratio was close to the theoretical value. However, in $\mathrm{Ni}_{1} \mathrm{Co}_{2}-\mathrm{ZIF}$ and $\mathrm{Ni}_{1} \mathrm{Co}_{4}-\mathrm{ZIF}$ samples, the doping ratio of $\mathrm{Ni}$ was far lower than the theoretical value, though the content was similar. Combined with XRD patterns, it was proven that Ni doping would affect the crystal stability, and Ni ions could hardly enter the crystal skeleton when the content of Co ions was high.
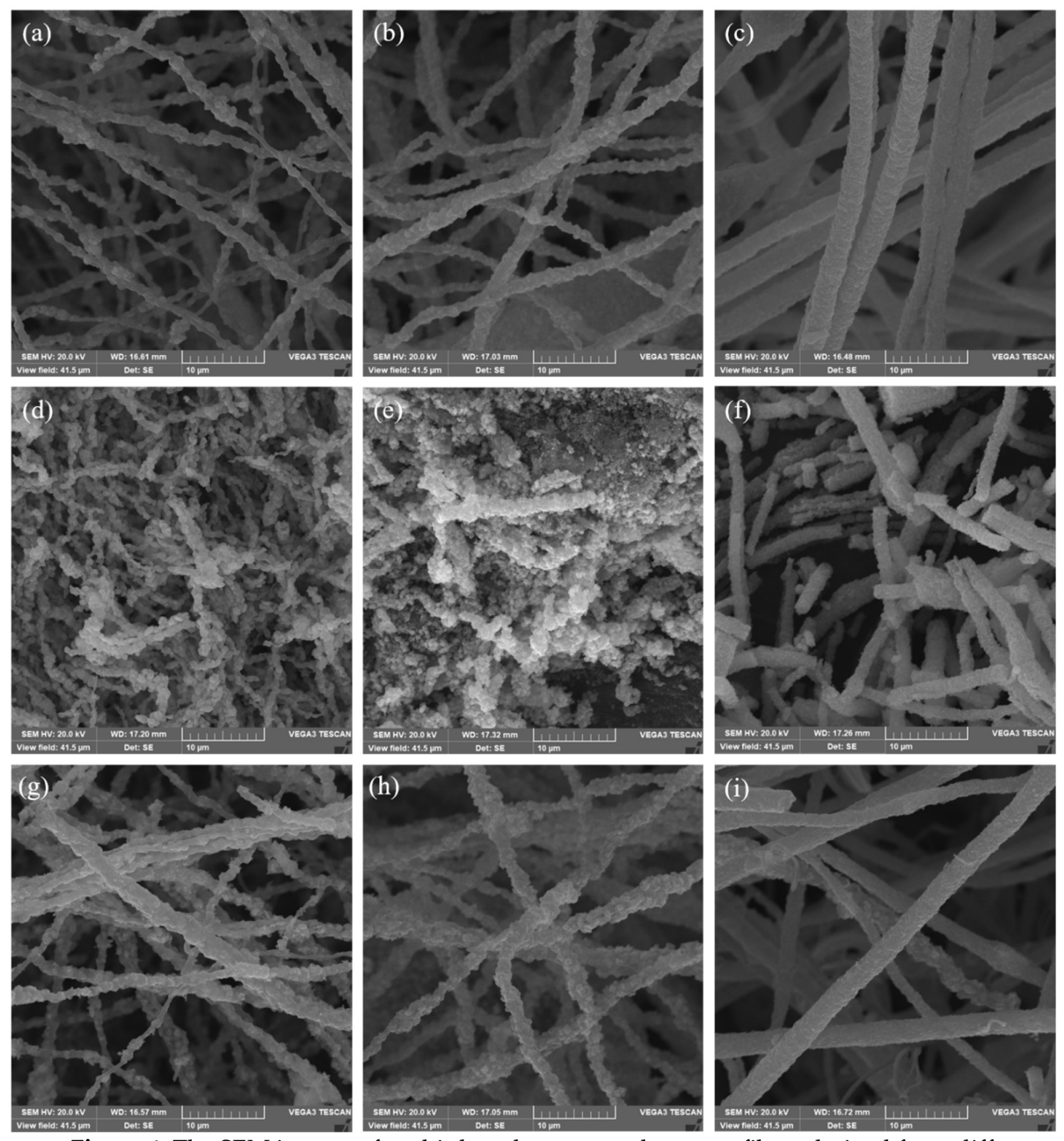

Figure 4. The SEM images of multi-doped porous carbon nanofibers derived from different $\mathrm{Ni}_{\mathrm{x}} \mathrm{Coy}_{\mathrm{y}} \mathrm{ZIFs} / \mathrm{PAN}$ nanofibers by carbonization, oxidation and sulfurization in different atmospheres (Ar, Air, and $\mathrm{H}_{2} \mathrm{~S}$ ): (a) Ni1Co1-ZIFs/PAN-Ar, (b) Ni1 Co2-ZIFs/PAN-Ar, (c) Ni1Co4-ZIFs/PAN-Ar; (d) Ni1Co1-ZIFs/PAN-Air, (e) Ni1Co2-ZIFs/PAN-Air, (f) Ni1Co4ZIFs/PAN-Air; (g) Ni1Co1-ZIFs/PAN-H2S, (h) Ni1Co2-ZIFs/PAN- $\mathrm{H}_{2} \mathrm{~S}$, (i) Ni1Co4ZIFs/PAN- $\mathrm{H}_{2} \mathrm{~S}$.

The microstructures of the varied samples under different atmosphere carbonization were characterized by SEM images shown in Figure 4. The nanofiber samples which were 
carbonized in Ar atmosphere maintained the rough surface morphology. After carbonization in Air, some nanofibers were found to be broken. During the carbonization process, the morphology of the nanofibers was the same as those under Ar gas after the sulfurization process. The results showed that the oxidation process after carbonization easily led to the destruction of the overall structure of the nanofiber. In contrast, the general morphology of the nanofiber did not change significantly during the carbonization process under the protection of inert Ar gas.
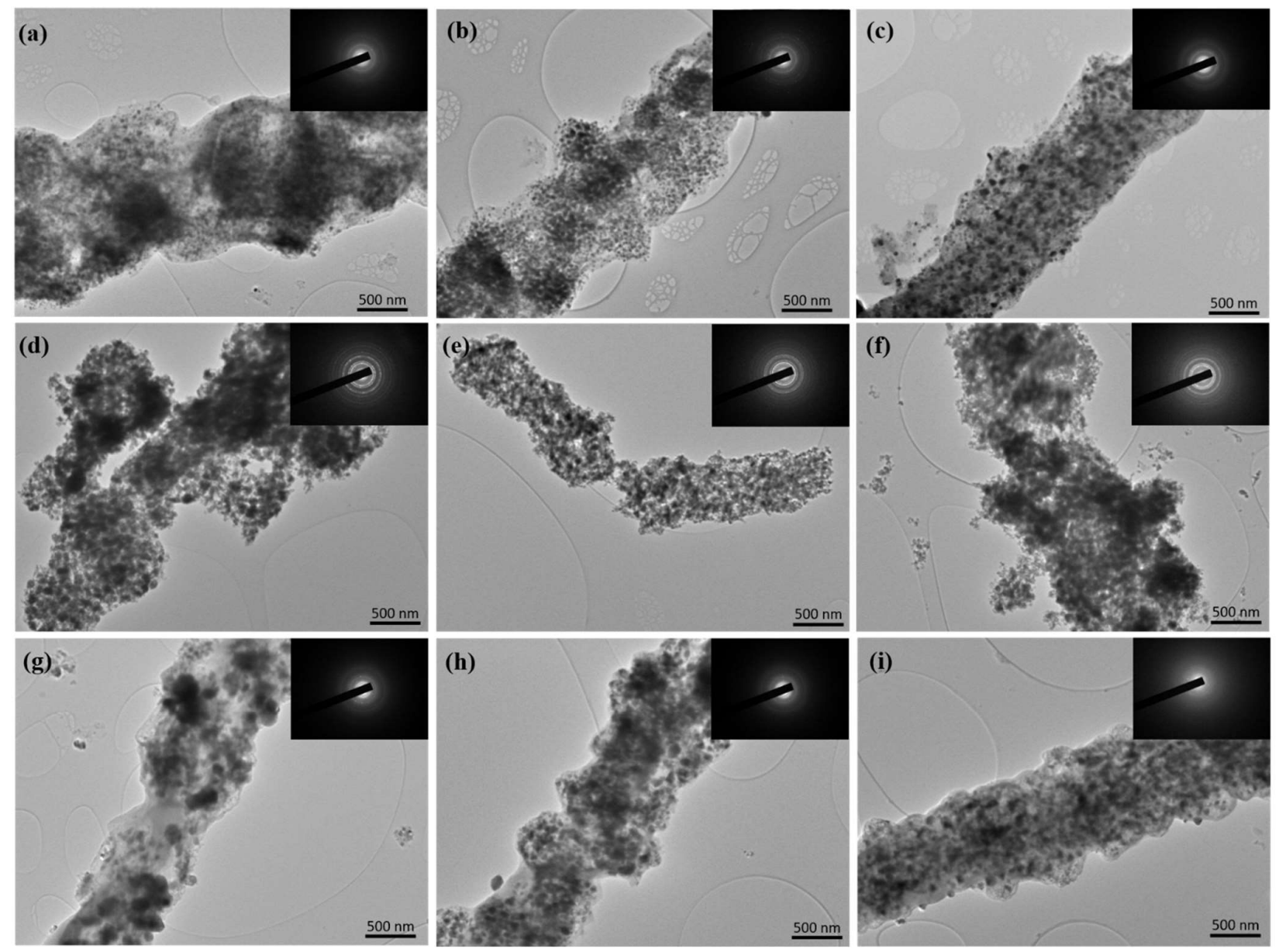

Figure 5. The TEM images of multi-doped porous carbon nanofibers derived from different $\mathrm{Ni}_{x} \mathrm{CO}_{y}$-ZIFs/PAN nanofibers by carbonization, oxidation and sulfurization in different atmospheres (Ar, Air, and $\mathrm{H}_{2} \mathrm{~S}$ ): (a) Ni1 Co1-ZIFs/PAN-Ar, (b) Ni1 Co2-ZIFs/PAN-Ar, (c) Ni1Co4-ZIFs/PAN-Ar; (d) Ni1Co1-ZIFs/PAN-Air, (e) Ni1Co2-ZIFs/PAN-Air, (f) Ni1Co4ZIFs/PAN-Air; (g) Ni1Co1-ZIFs/PAN- H2S, (h) NicCo2-ZIFs/PAN- H2S, (i) Ni1Co4ZIFs/PAN- $\mathrm{H}_{2} \mathrm{~S}$.

The internal structure of carbonized samples was additionally characterized by TEM images, as displayed in Figure 5. Many metal nanoparticles were observed on nanofibers after carbonization in Ar atmosphere (Figure 5a-c). Before carbonization, the outline of the $\mathrm{Ni}_{\mathrm{x}} \mathrm{Coy}_{\mathrm{Z}} \mathrm{ZIF}$ crystals was much prominent. The nanoparticles derived from Ni1.Co4ZIFs/PAN precursors were relatively small and uniform. After oxidation in Air, the derived nanoparticles became larger, and some nanofibers broke (Figure 5d-f). The obtained results were coherent with the SEM images. After the sulfurization process, agglomeration of nanoparticles occurred. However, the morphology and distinct pore structure were still maintained (Figure 5g-i). From the crystal diffraction pattern (Figure 5 inserted), it was observed that the samples obtained by carbonization in different atmospheres had 
good crystal structure, among which the crystal diffraction ring structure after oxidation was the most distinct. At the same time, the catalysts derived from Ni1Co4-ZIFs/PAN had uniform nanoparticle doping and a complete nanofiber structure.
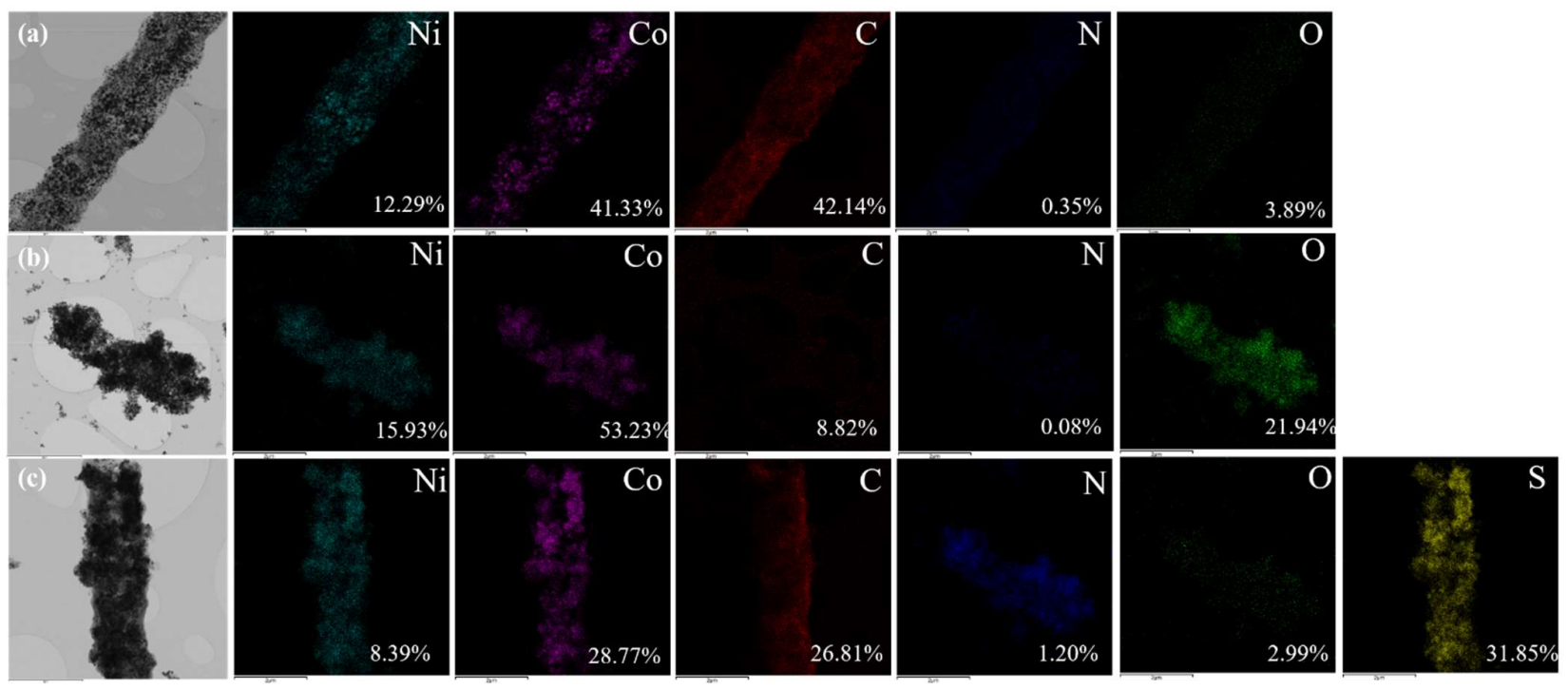

Figure 6. The TEM images and elemental mappings of multi-doped porous carbon nanofibers derived from $\mathrm{Ni}_{1} \mathrm{Co}$-ZIFs/PAN nanofibers by (a) carbonization, (b) oxidation, and (c) sulfurization in different atmospheres (Ar, Air, and $\mathrm{H}_{2} \mathrm{~S}$ ) at $800^{\circ} \mathrm{C}$.

Furthermore, the TEM images and elemental mappings of multi-doped porous carbon nanofibers derived from Ni1 Co4-ZIF/PAN nanofibers by carbonization, oxidation, and sulfurization in different atmospheres ( $\mathrm{Ar}, \mathrm{Air}$, and $\mathrm{H}_{2} \mathrm{~S}$ ) at $800^{\circ} \mathrm{C}$ is shown in Figure 6. After carbonization, all the ratio of $\mathrm{Ni}$ and $\mathrm{Co}$ was close to the theoretical ratio before carbonization. During carbonization in only Ar atmosphere, the carbon element content remained at $42.14 \%$. After oxidation treatment in the Air, oxygen content increased as expected to $21.94 \%$, while carbon content decreased to $8.82 \%$, which may be due to the generation of carbon dioxide. After the sulfurization process, it was found that there were a lot of sulfur elements up to about $31.85 \%$. 

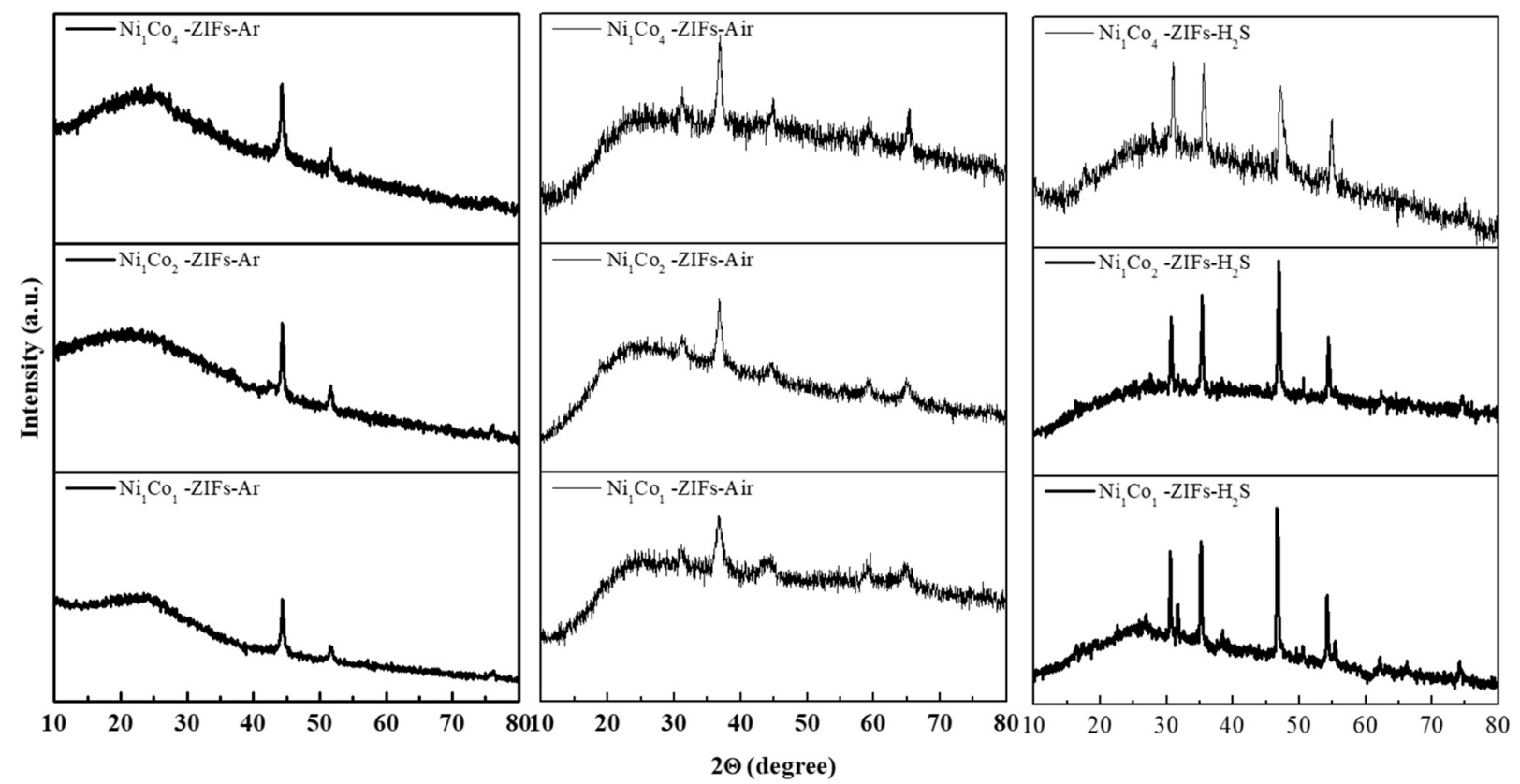

Figure 7. The XRD patterns of multi-doped porous carbon nanofibers derived from different $\mathrm{Nix}_{x} \mathrm{Coy}_{\mathrm{Z}} \mathrm{ZIF} / \mathrm{PAN}$ nanofibers by carbonization, oxidation, and sulfurization in different atmospheres (Ar, Air, and $\mathrm{H}_{2} \mathrm{~S}$ ) at $800^{\circ} \mathrm{C}$

From Figure 7, the XRD characterization was done to study the crystal composition changes in different carbonization atmospheres. For $\mathrm{Nix}_{x} \mathrm{Co}_{y}$-ZIFs/PAN-Ar, the XRD pattern showed the diffraction peaks of two main metallic elements at $44.5^{\circ}$ and $51.8^{\circ}$, which proved that $\mathrm{Ni}_{x} \mathrm{CO}_{y}$ alloy metal doping was realized [25]. Examining $\mathrm{Ni}_{x} \mathrm{Co}_{y}-\mathrm{ZIFs} / \mathrm{PAN}-$ Air, the XRD pattern revealed diffraction peaks of multiple metal oxides at $36.8^{\circ}$, $44.3^{\circ}, 59.8^{\circ}$, and $65.0^{\circ}$, indicating $\mathrm{Nix}_{\mathrm{C}} \mathrm{Coy}_{\mathrm{y}}$ metal oxides doping was achieved [26,27]. Moreover, the XRD patterns of $\mathrm{Nix}_{x} \mathrm{Coy}_{y} \mathrm{ZIFs} / \mathrm{PAN}-\mathrm{H}_{2} \mathrm{~S}$ offered $\mathrm{Ni}_{x} \mathrm{Coy}_{y}$ metallic sulfide diffraction peaks at $30.8^{\circ}, 35.1^{\circ}, 47.2^{\circ}$, and $54.7^{\circ}$, which affirmed multiple metallic sulfide doping. Hence, the results above demonstrated that carbonization could be used to prepare catalyst materials with various doping types in different atmospheres [21,28].
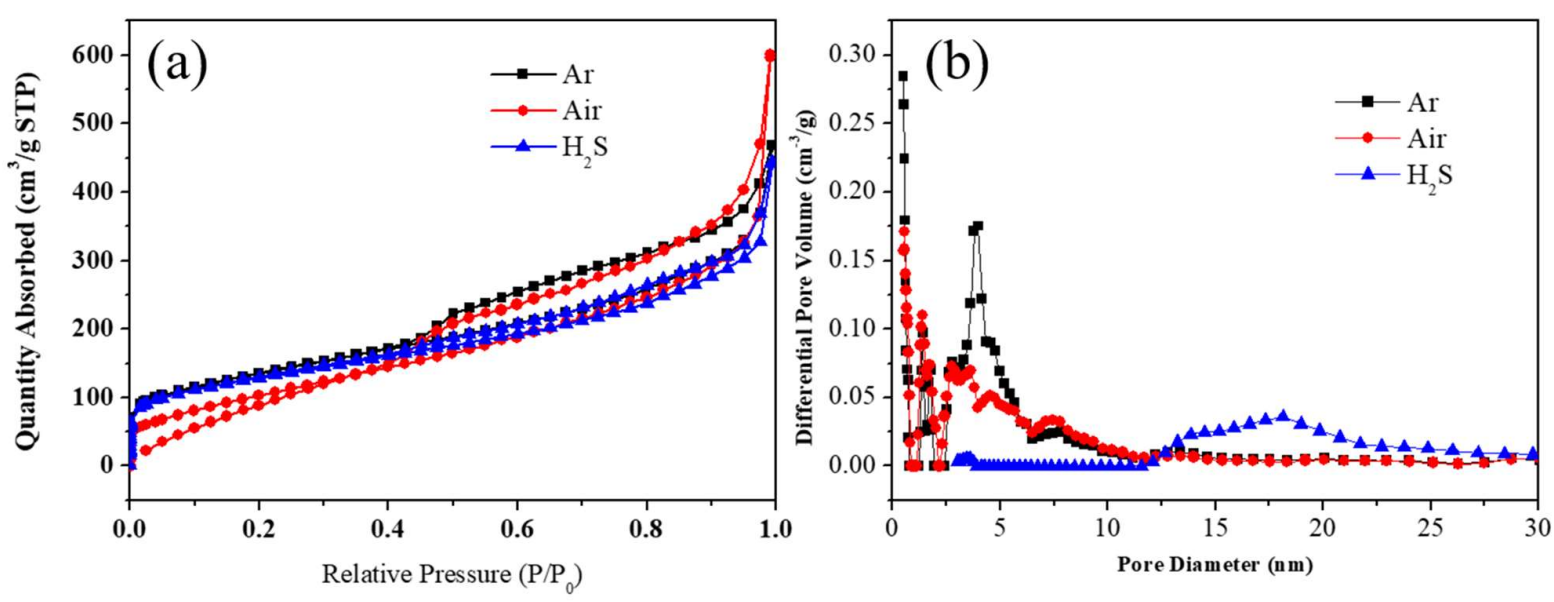

Figure 8. The (a) $\mathrm{N}_{2}$ sorption isotherm plots and (b) pore size distribution curves of multidoped porous carbon nanofibers derived from different $\mathrm{Ni}_{1} \mathrm{Co} 4-\mathrm{ZIF} / \mathrm{PAN}$ nanofibers by carbonization, oxidation, and sulfurization in different atmospheres ( $\mathrm{Ar}$, $\mathrm{Air}$, and $\mathrm{H}_{2} \mathrm{~S}$ ) at $800^{\circ} \mathrm{C}$. 
The effects of different carbonization processes on specific surface area and porosity were examined using nitrogen sorption curves of the materials (Figure 8). The catalyst specific surface area gained by carbonization in Ar atmosphere was $484.265 \mathrm{~m}^{2} \mathrm{~g}^{-1}$, while the pore size distribution was primarily centered at about $5 \mathrm{~nm}$. After Air oxidation, it was found that the hysteresis region of nitrogen adsorption and desorption curve has no apparent change. The distribution was primarily concentrated below $10 \mathrm{~nm}$. It was noted that the hysteresis of nitrogen adsorption and desorption curve decreased after sulfurization, whereas the distribution of the pore sizes increased to $15-20 \mathrm{~nm}$. The pore structure and specific surface area tend to affect the catalytic performance of catalysts.
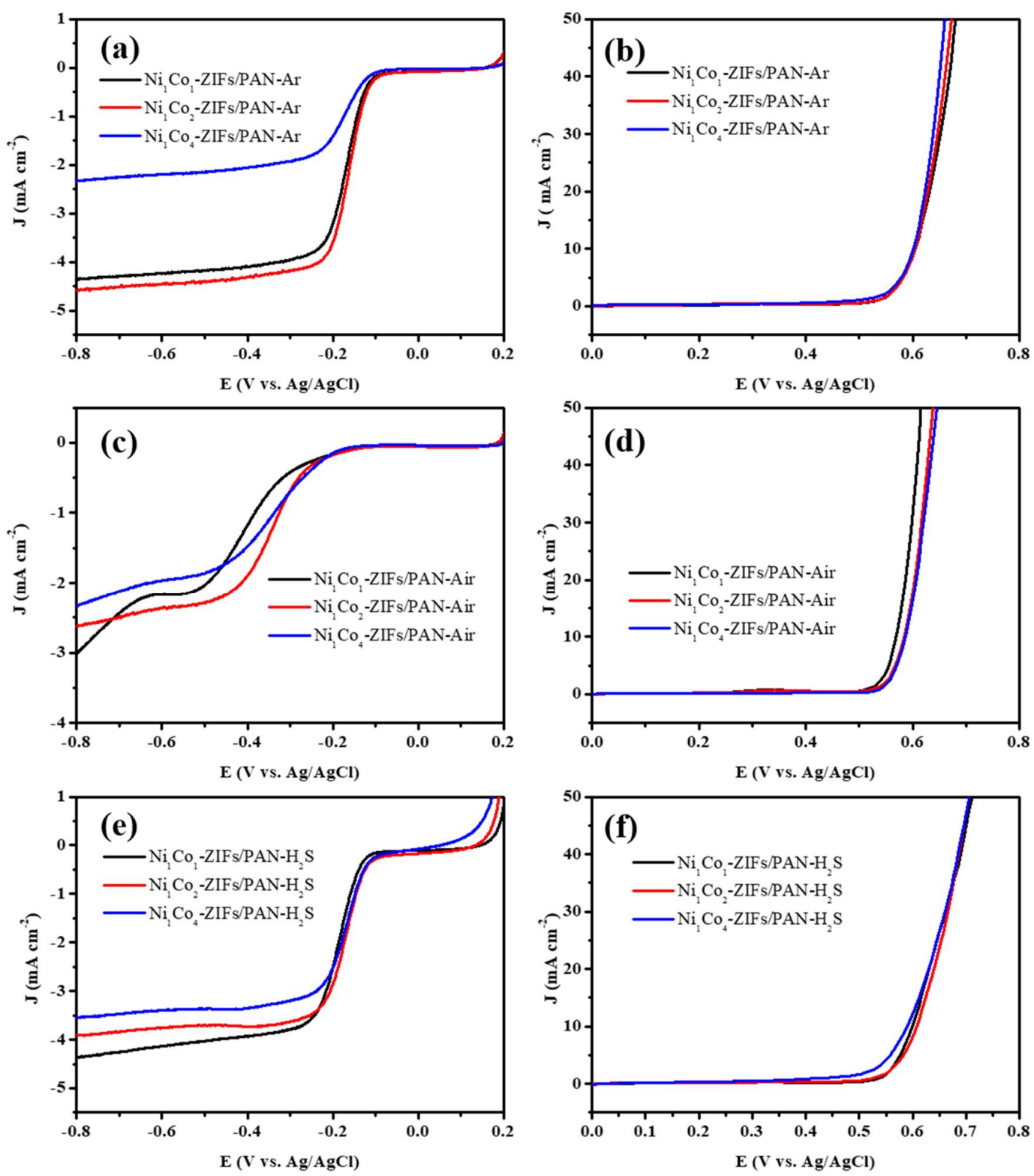

Figure 9. The ORR and OER performances of multi-doped porous carbon nanofibers derived from different $\mathrm{Ni}_{\mathrm{x}} \mathrm{Coy}_{\mathrm{y}} \mathrm{ZIF} / \mathrm{PAN}$ nanofibers by carbonization, oxidation, and sulfurization in different atmospheres (Ar, Air, and $\mathrm{H}_{2} \mathrm{~S}$ ) at $800^{\circ} \mathrm{C}$.

The ORR and OER performances under different carbonization states were studied. As depicted in Figure 9a, the $\mathrm{Ni}_{1} \mathrm{CO}_{2}-\mathrm{ZIFs} / \mathrm{PAN}$-Ar sample had the best ORR output. In 
terms of OER behavior in Nix Coy-ZIFs/PAN-Ar samples (Figure 9b), there were no significant changes in potential value at $10 \mathrm{~mA} \cdot \mathrm{cm}^{-2}$. Figure 9c showed that the ORR of $\mathrm{Ni}_{x} \mathrm{Coy}^{-}$ ZIFs/PAN-Air decreased after the oxidation process. However, their OER performances were significantly enhanced, especially for Ni1Co1-ZIFs/PAN-Air (Figure 9d). After the sulfurization process (Figure 9e), the ORR yields were better than oxidation but worse than carbonation products in the Ar atmosphere. After sulfurization, the OER performance of $\mathrm{Ni}_{1} \mathrm{Co}_{4}-\mathrm{ZIF} / \mathrm{PAN}-\mathrm{H}_{2} \mathrm{~S}$ was better than the other samples (Figure 9f). In addition, it was observed from Figure 9a, 9c, and 9e that when the ratio of Ni/Co was 1/2, their ORR catalytic performance was better than the other ratios. Meanwhile, as illustrated in Figure $9 \mathrm{~b}$ and $9 \mathrm{f}$, when the ratio of $\mathrm{Ni} / \mathrm{Co}$ was $1 / 4$, their OER catalytic performances were better compared to the other ratios.

\section{Conclusion}

In summary, bimetallic $\mathrm{Ni}_{x} \mathrm{Co}_{y}-\mathrm{ZIFs}$ were prepared by hydrothermal synthesis. The best crystalline structure was achieved when the Ni/Co ratio was $1 / 4$. One-dimensional $\mathrm{Ni}_{\mathrm{x}} \mathrm{Co}_{\mathrm{y}}$-ZIFs/PAN nanofiber precursors were synthesized by simple electrospinning. Subsequently, $\mathrm{Nix}$ Coy bimetallic compound doped porous carbon nanofiber catalysts with $\mathrm{N}$, $\mathrm{O}, \mathrm{S}$ doping were obtained by carbonization under different gas (Ar, Air, $\mathrm{H}_{2} \mathrm{~S}$ ) atmospheres, respectively. The morphology, structure, crystal composition, elemental content, and specific surface area of the carbonized catalysts were characterized by SEM, TEM, XRD, elemental mapping and BET. The carbon content of the nanofiber decreased, and the nanoparticles agglomerated during the oxidation process, leading to nanofiber fracture. The S-doping reduced the specific surface area and increased the nanofiber pore size. Importantly, it was found that $\mathrm{Ni}_{1} \mathrm{Co}_{2}-\mathrm{ZIF} / \mathrm{PAN}-\mathrm{Ar}$ and $\mathrm{Ni} \mathrm{Co}_{1}-\mathrm{ZIF} / \mathrm{PAN}-\mathrm{Air}$ yielded the best results for ORR and OER performances after the carbonization process, respectively.

Author Contributions: Conceptualization, N.N.W. and. Y.Q.Z.; experiment, Q.J.N.; writing-original draft preparation, T.W., O.O. and Y.H.L.; writing-review and editing Q.J.N., M.F.D. and L.C.; project administration, Q.J.N.; funding acquisition, Q.J.N., and L.C. All authors have read and agreed to the published version of the manuscript.

Funding: This research was funded by China Postdoctoral Science Foundation (Grant no. 2020M671359); Natural Science Foundation of Jiangsu Province (Grant no. BK20200914); National Natural Science Foundation of China (Grant no. 62101216); Priority Academic Program Development of Jiangsu Higher Education Institutions (Grant no. PAPD-2018-87) and Jiangsu Distinguished professor and Jiangsu Province Key project of Research and Development Plan (Grant no. BE2020676.)

Data Availability Statement: The data presented in this study are available on request from the corresponding author.

Conflicts of Interest: The authors declare no conflict of interest.

\section{References}

1. Wu, G.; Santandreu, A.; Kellogg, W.; Gupta, S.; Ogoke, O.; Zhang, H.; Wang, H.-L.; Dai, L. Carbon nanocomposite catalysts for oxygen reduction and evolution reactions: From nitrogen doping to transition-metal addition. Nano Energy 2016, 29, 83110, doi:10.1016/j.nanoen.2015.12.032.

2. Ruan, M.; Liu, J.; Song, P.; Xu, W. Meta-analysis of commercial Pt/C measurements for oxygen reduction reactions via data mining. Chinese J. Catal. 2022, 43, 116-121, doi:10.1016/S1872-2067(21)63854-8.

3. Gonzalez-Huerta, R.G.; Ramos-Sanchez, G.; Balbuena, P.B. Oxygen evolution in Co-doped $\mathrm{RuO}_{2}$ and $\mathrm{IrO}_{2}$ : Experimental and 
theoretical insights to diminish electrolysis overpotential. J. Power Sources 2014, 268, 69-76, doi:10.1016/j.jpowsour.2014.06.029.

4. Wu, X.; Niu, Y.; Feng, B.; Yu, Y.; Huang, X.; Zhong, C.; Hu, W.; Li, C.M. Mesoporous Hollow Nitrogen-Doped Carbon Nanospheres with Embedded MnFe2O4/Fe Hybrid Nanoparticles as Efficient Bifunctional Oxygen Electrocatalysts in Alkaline Media. ACS Appl. Mater. Interfaces 2018, 10, 20440-20447, doi:10.1021/acsami.8b04012.

5. Ma, L.-L.; Hu, X.; Liu, W.-J.; Li, H.-C.; Lam, P.K.S.; Zeng, R.J.; Yu, H.-Q. Constructing N, P-dually doped biochar materials from biomass wastes for high-performance bifunctional oxygen electrocatalysts. Chemosphere 2021, 278, 130508, doi:10.1016/j.chemosphere.2021.130508.

6. Sun, J.; Lowe, S.E.; Zhang, L.; Wang, Y.; Pang, K.; Wang, Y.; Zhong, Y.; Liu, P.; Zhao, K.; Tang, Z. Ultrathin nitrogen-doped holey carbon@ graphene bifunctional electrocatalyst for oxygen reduction and evolution reactions in alkaline and acidic media. Angew. Chemie Int. Ed. 2018, 57, 16511-16515, doi:10.1002/anie.201811573.

7. Morales, D.M.; Kazakova, M.A.; Dieckhöfer, S.; Selyutin, A.G.; Golubtsov, G. V; Schuhmann, W.; Masa, J. Trimetallic Mn-Fe$\mathrm{Ni}$ oxide nanoparticles supported on multi-walled carbon nanotubes as high-performance bifunctional ORR/OER electrocatalyst in alkaline media. Adv. Funct. Mater. 2020, 30, 1905992, doi:10.1002/adfm.201905992.

8. Zhang, W.; Yao, X.; Zhou, S.; Li, X.; Li, L.; Yu, Z.; Gu, L. ZIF-8/ZIF-67-derived Co-Nx-embedded 1D porous carbon nanofibers with graphitic carbon-encased Co nanoparticles as an efficient bifunctional electrocatalyst. Small 2018, 14, 1800423, doi:10.1002/smll.201800423.

9. Meng, Y.; Huang, X.; Lin, H.; Zhang, P.; Gao, Q.; Li, W. Carbon-based nanomaterials as sustainable noble-metal-free electrocatalysts. Front. Chem. 2019, 7, 759, doi:10.3389/fchem.2019.00759.

10. Osgood, H.; Devaguptapu, S. V.; Xu, H.; Cho, J.; Wu, G. Transition metal (Fe, Co, Ni, and Mn) oxides for oxygen reduction and evolution bifunctional catalysts in alkaline media. Nano Today 2016, 11, 601-625, doi:10.1016/j.nantod.2016.09.001.

11. Hu, C.; Paul, R.; Dai, Q.; Dai, L. Carbon-based metal-free electrocatalysts: from oxygen reduction to multifunctional electrocatalysis. Chem. Soc. Rev. 2021, doi:10.1039/D1CS00219H.

12. Chen, Z.; Zhao, B.; He, Y.-C.; Wen, H.-R.; Fu, X.-Z.; Sun, R.; Wong, C.-P. NiCo2 $\mathrm{O}_{4}$ nano-frames with a nanosheet surface as efficient electrocatalysts for the oxygen evolution reaction. Mater. Chem. Front. 2018, 2, 1155-1164, doi:10.1039/C8QM00027A.

13. Faraji, M.; Arianpouya, N. NiCoFe-layered double hydroxides/MXene/N-doped carbon nanotube composite as a high performance bifunctional catalyst for oxygen electrocatalytic reactions in metal-air batteries. J. Electroanal. Chem. 2021, 901, 115797, doi:10.1016/j.jelechem.2021.115797.

14. Lian, Y.; Shi, K.; Yang, H.; Sun, H.; Qi, P.; Ye, J.; Wu, W.; Deng, Z.; Peng, Y. Elucidation of Active Sites on S, N Codoped Carbon Cubes Embedding Co-Fe Carbides toward Reversible Oxygen Conversion in High-Performance Zinc-Air Batteries. Small 2020, 16, 1907368, doi:10.1002/smll.201907368.

15. Yan, S.; Luo, C.; Zhang, H.; Yang, L.; Huang, N.; Zhang, M.; Yu, H.; Sun, P.; Wang, L.; Lv, X.; et al. In-Situ derived Co1xS@nitrogen-doped carbon nanoneedle array as a bifunctional electrocatalyst for flexible Zinc-air battery. J. Electroanal. Chem. 2021, 900, 115711, doi:10.1016/j.jelechem.2021.115711.

16. Vijayakumar, E.; Ramakrishnan, S.; Sathiskumar, C.; Yoo, D.J.; Balamurugan, J.; Noh, H.S.; Kwon, D.; Kim, Y.H.; Lee, H. MOF-derived CoP-nitrogen-doped carbon@NiFeP nanoflakes as an efficient and durable electrocatalyst with multiple catalytically active sites for OER, HER, ORR and rechargeable zinc-air batteries. Chem. Eng. J. 2022, 428, 131115, doi:10.1016/j.cej.2021.131115.

17. Lei, Y.; Wang, Q.; Peng, S.; Ramakrishna, S.; Zhang, D.; Zhou, K. Electrospun Inorganic Nanofibers for Oxygen Electrocatalysis: Design, Fabrication, and Progress. Adv. Energy Mater. 2020, 10, 1902115, doi:10.1002/aenm.201902115.

18. Li, Y.; Zhu, J.; Cheng, H.; Li, G.; Cho, H.; Jiang, M.; Gao, Q.; Zhang, X. Developments of Advanced Electrospinning Techniques: A Critical Review. Adv. Mater. Technol. 2021, 6, 2100410, doi:10.1002/admt.202100410.

19. Wang, H.-F.; Chen, L.; Pang, H.; Kaskel, S.; Xu, Q. MOF-derived electrocatalysts for oxygen reduction, oxygen evolution and hydrogen evolution reactions. Chem. Soc. Rev. 2020, 49, 1414-1448, doi:10.1039/C9CS00906J. 
20. Li, H.; Wu, G.; Cheng, G.; Shuai, Y.; Liu, S.; Liu, Y. CoNi nano-alloys embedded in N-doped carbon nanofibers derived from layered bimetal-organic framework and as efficient oxygen electrocatalyst. J. Alloys Compd. 2021, 888, 161588, doi:10.1016/j.jallcom.2021.161588.

21. Chen, B.; Ma, G.; Zhu, Y.; Wang, J.; Xiong, W.; Xia, Y. Metal-organic-framework-derived bi-metallic sulfide on N, S-codoped porous carbon nanocomposites as multifunctional electrocatalysts. J. Power Sources 2016, 334, 112-119, doi:10.1016/j.jpowsour.2016.10.022.

22. Niu, Q.; Chen, B.; Guo, J.; Nie, J.; Guo, X.; Ma, G. Flexible, Porous, and Metal-Heteroatom-Doped Carbon Nanofibers as Efficient ORR Electrocatalysts for Zn-Air Battery. Nano-Micro Lett. 2019, 11, 8, doi:10.1007/s40820-019-0238-4.

23. Niu, Q.; Ola, O.; Chen, B.; Zhu, Y.; Xia, Y.; Ma, G. Metal Sulfide Nanoparticles Anchored N, S Co-doped Porous Carbon Nanofibers as Highly Efficient Bifunctional Electrocatalysts for Oxygen Reduction/Evolution Reactions. Int. J. Electrochem. Sci. 2020, 15, doi:10.20964/2020.06.28.

24. Niu, Q.; Ola, O.; Wang, N.; Chen, B.; Zhu, Y.; Xia, Y. Carbon encapsulated WS2 nanocomposites derived from ZIF-67@ WS2 Core-Shell Nanoparticles and their electrocatalytic applications. Int. J. Electrochem. Sci. 2020, 15, doi:10.20964/2020.12.85.

25. Peng, W.; Jin, J.; Yang, S.; Shen, Z.; Wang, H.; Zhang, J.; Li, G. NiCo Alloy Nanoparticles Anchored on Carbon NanotubeDecorated Carbon Nanorods as a Durable and Efficient Oxygen Electrocatalyst for Zinc-Air Flow Batteries. ACS Appl. Energy Mater. 2021, 4, 11041-11050, doi:10.1021/acsaem.1c01967.

26. Liu, C.; Zuo, P.; Jin, Y.; Zong, X.; Li, D.; Xiong, Y. Defect-enriched carbon nanofibers encapsulating NiCo oxide for efficient oxygen electrocatalysis and rechargeable Zn-air batteries. J. Power Sources 2020, 473, 228604, doi:10.1016/j.jpowsour.2020.228604.

27. Belkessam, C.; Bencherif, S.; Mechouet, M.; Idiri, N.; Ghilane, J. The Effect of Heteroatom Doping on Nickel Cobalt Oxide Electrocatalysts for Oxygen Evolution and Reduction Reactions. Chempluschem 2020, 85, 1710-1718, doi:10.1002/cplu.202000436.

28. Chen, B.; Li, R.; Ma, G.; Gou, X.; Zhu, Y.; Xia, Y. Cobalt sulfide/N,S codoped porous carbon core-shell nanocomposites as superior bifunctional electrocatalysts for oxygen reduction and evolution reactions. Nanoscale 2015, 7, 20674-20684, doi:10.1039/C5NR07429K. 